\section{CYCLOPROPANE ANESTHESIA}

By Benjamin Howard Robbins, B.A., M.S., M.D., Professor of Anesthesiology and Associate Professor of Pharmacology, Vanderbilt University School of Medicine. Second edition. Pp. 293. London: Baillière, Tindall \& Cox. $72 s$.

Anaesthetists and others interested in the scientific study of cyclopropane, will welcome this new edition of Dr. Robbins's book. About two-thirds of it is devoted to an excellent, detailed description of the pharmacological actions of this anaesthetic and is, in part, based upon the experimental work with which Dr. Robbins and his collaborators have been associated over the years. This enhances the value of the book to those doctors primarily concerned with the laboratory investigation of inhalational drugs, but, for the more clinically minded, each chapter finishes with a lucid and helpful summary of its contents. That part of the book devoted to the clinical aspects of cyclopropane anaesthesia is less valuable, perhaps because the passage of time has tended to modify the opinions quoted from some of the references. It also seems a pity that no mention is made of the pioneer work of Hingson in the U.S.A. and Bourne in this country on the use of cyclopropane in midget apparatus for minor operations, particularly on outpatients.

\section{PERIPHERAL NERVE INJURIES}

By Ruth E. M. Bowden. Pp. xiii +62 , with 30 diagrams. London: H. K. Lewis \& Co. Ltd. 1958. 8s. 6 d.

This book, only 57 pages long including 30 illustrations, answers a long-felt need for a short, concise textbook in the "introduction to methods of diagnosis and treatment of nerve injuries.' This is the task that Miss Bowden has set herself and she has succeeded well. It is expressly designed to 'meet the needs of physiotherapists, medical students and housemen and to be an aide memoire to their seniors.'

There are seven chapters in this book and, successively, they are: Classifications (9 pages), methods of examination and diagnosis (8 pages), electrodiagnosis (4 pages), anatomy (20 pages), treatment (5 pages), definitive surgical treatment (4 pages), and conservative treatment (6 pages).

It is not surprising to find the emphasis on anatomy since Miss Bowden is professor in that subject, and indeed the subject of peripheral nerve injuries demands accurate knowledge of anatomy. However, to devote 20 out of 57 pages to anatomy does seem a little unbalanced in a book designed for those who have recently studied anatomy. The plea for early diagnosis and reference to a specialist department would seem to be the main motive for this excellent book.

The commendable brevity and condensation of the material into 57 pages will form the chief attraction to undergraduate students whose time for reading specialist subjects is inevitably limited. The two hours spent in studying this book will be well worth while. On page 27 we find the phrase ' coalescence of one or more ganglia.' Must there not be two or more to form a coalescence?

It is to be hoped that this book will be widely read for if it leads to early diagnosis (and it is to the Casualty Officer that the problem is mainly presented in peacetime), and consequent treatment, better results can be expected. The book is well produced with good, clear type and bold illustrations, and at 8s. 6d. is not expensive.

\section{REHABILITATION OF THE HAND}

By C. B. WYNN-PARRY, M.B.E., M.A., D.M., D.Phys.Med. First Edition. Pp. vii +273 + index. London, Butterworth \& Co., Ltd. 1958. Price 45s.

Squadron-Leader Wynn-Parry calls his book Rehabilitation of the Hand, and of course the Hand is its main concern. Clearly though, it is impossible to separate the hand from the upper limb as a whole, and the author has very wisely avoided trying to make this artificial division. Indeed, his book covers the subject in its broader aspect so well that it might well be named Rehabilitation of the Upper Limb. The clear account of functional anatomy and of methods of examination is followed by useful sections dealing with injuries of tendons and of peripheral nerves. Complementary to the latter is the chapter on electrodiagnosis, in which an excellent and well-balanced account of these methods is given. Wynn-Parry's long experience and original work in this field have enabled him to make this chapter of real value and of great importance to all who have to deal with nerve injuries. Stiffness of the hand merits a separate chapter, in which the important causes of stiffness are considered and methods of treatment are described. Three further chapters deal with upper limb weakness, techniques of treatment and methods of resettlement, and D. A. Brewerton and D. $M$. Brooks contribute respectively excellent sections on the Rheumatoid Hand and on reconstruction of the injured hand.

Perhaps the two special merits of this important book are that it concentrates in one volume much that hitherto has had to be sought for in many books, and that it gives detailed descriptions of methods of treatment, of appropriate methods of occupational therapy and of the making of appliances. The author is of course very fortunately placed in being able to give a comprehensive account of rehabilitation of the injured hand from the time of injury to the time of final discharge. He and his colleagues have succeeded in doing this by efficient handling and good presentation of their large amount of material. As to the second special merit: all workers in this field will be grateful to SquadronLeader Wynn-Parry for the clear and comprehensive 